\title{
Erratum to: Parasitic nematode communities of the red kangaroo, Macropus rufus: richness and structuring in captive systems
}

\author{
M. J. Lott ${ }^{1}$ - G. C. Hose ${ }^{1}$ - M. L. Power ${ }^{1}$
}

Published online: 19 June 2015

(C) Springer-Verlag Berlin Heidelberg 2015

Erratum to: Parasitology Research

DOI 10.1007/s00436-015-4494-z

The original version of the above article contained a mistake in the text. The line ' $\ldots$ clustered using the furthest neighbour algorithm with a minimum identity threshold of $93 \%$ ' should be '.. clustered using the furthest neighbour algorithm with a minimum identity threshold of $97 \%$ '.

The online version of the original article can be found at http://dx.doi.org/ 10.1007/s00436-015-4494-z.

\footnotetext{
M. J. Lott

matthew.lott@mq.edu.au

1 Department of Biological Sciences, Macquarie University,

Sydney, NSW 2109, Australia
} 